\title{
P84 Co-Polyimide-based Tubular Carbon Membrane: Effect of Pyrolysis Temperature
}

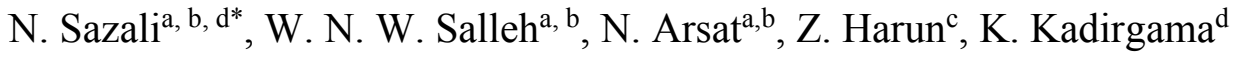 \\ ${ }^{a}$ Advanced Membrane Technology Research Centre (AMTEC), Universiti Teknologi \\ Malaysia, 81310 UTM Johor Bahru, Johor, Malaysia \\ ${ }^{\mathrm{b}}$ School of Chemical and Energy Engineering (SCEE), Universiti Teknologi \\ Malaysia, 81310 UTM Johor Bahru, Johor, Malaysia \\ ${ }^{c}$ Advanced Manufacturing and Materials Centre (AMMC), Faculty of Mechanical and \\ Manufacturing Engineering, Universiti Tun Hussein Onn Malaysia, 86400 Parit Raja, \\ Johor, Malaysia \\ ${ }^{\mathrm{d}}$ Faculty of Mechanical Engineering, Universiti Malaysia Pahang, \\ 26600 Pekan Pahang Darul Makmur, Malaysia
}

Submitted: 20/5/2018. Revised edition: 8/7/2018. Accepted: 8/7/2018. Available online: 5/12/2018

\begin{abstract}
In this study, the effect of carbonization temperature on the performance of carbon membrane was being investigated. P84 co-polyimide-based tubular carbon membrane were fabricated through the dip-coating technique. The prepared membranes were characterized by using the thermogravimetric analysis and scanning electron microscopy. $\mathrm{CO}_{2}, \mathrm{~N}_{2}$, and $\mathrm{CH}_{4}$ pure gas were utilized in determination of the carbon membrane's permeation attributes. In order to enhance the membrane's performance, carbonization process was performed in Ar environment; with the flow rate of $200 \mathrm{ml} / \mathrm{min}$. The carbonization process was done at various temperature, namely $600{ }^{\circ} \mathrm{C}, 700{ }^{\circ} \mathrm{C}, 800{ }^{\circ} \mathrm{C}$ and $900{ }^{\circ} \mathrm{C}$ in a constant heating rate of $3{ }^{\circ} \mathrm{C} / \mathrm{min}$. The increased in the temperature of carbonization leads to the production of small pores size carbon membrane. Carbon membrane prepared at $800{ }^{\circ} \mathrm{C}$ showed the highest $\mathrm{CO}_{2} / \mathrm{CH}_{4}$ and $\mathrm{CO}_{2} / \mathrm{N}_{2}$ selectivity of $63.2 \pm 5.2$ and $61.3 \pm 1.7$, respectively.
\end{abstract}

Keywords: Tubular carbon membrane, carbonization process, gas separation, P84 co-polyimide

\subsection{INTRODUCTION}

Separation of gas through membrane offers advantage such as ease of operation which can effectively fit onto the power plant with no complex incorporation and devoid of chemicals addition and absorbent or adsorbent regeneration is completely dismissed [1]. Membrane technology is believed to be sensible and compelling innovations for the division of vaporous blends at the modern scale due to their high vitality productive partition process, clear task and low capital and working costs [2]. Of late, worldwide has shown enthusiasm toward thinking about inorganic materials to supplant the current polymeric materials. Similarly, they accept a critical part in the gas partition procedure of mechanical segment as a result of its capability to isolate the little particles of gasses adequately [3-5]. Carbonization is a procedure in which an appropriate carbon forerunner is burned in a controlled atmosphere (vacuum or inactive) to the carbonization temperature at a specific warming rate for an adequately long warm drench time $[6,7]$.

\footnotetext{
* Corresponding to: N. Sazali (email: melya.jandi@yahoo.com)

https://doi.org/10.11113/amst.v23n1.121
} 
The sorts of polymer being utilized as a precursor assume a critical part in the readiness of carbon membranes. Polyimides are one of the best options because they are inflexible, has high dissolving point as well as high glass progress temperature, $\mathrm{Tg}$ [8]. Subsequently, polyimides are considered as the most stable of all polymers. The most generally business polyimide used for manufacture of carbon membrane is P84 co-polyimide. It can be broken up in numerous solvents and P84 co-polyimide-based tubular carbon membrane has a decent compound and warm security besides having an amazing detachment factor.

The polymeric membranes can be manufactured either as unsupported membranes or upheld membranes. A really cautious dealing with it is required for carbon membranes as a result of the delicacy of carbon membrane [9]. It makes them difficult to be created especially for bigger surface zone of membranes. Of course, this issue can be overwhelmed by showing supported carbon membranes either tube or flat-sheet. The mechanical quality exceedingly permeable materials can likewise be upgraded by covering their surfaces. There are a few types of covering systems; splash covering, turn covering, plunge covering and ultrasonic statement. In this investigation, tubular held membrane was set up by plunge covering strategy due to its straightforwardness and financially savvy as has been enhanced by numerous researchers $[2,10]$.

\subsection{METHODS}

\subsection{Materials}

In this investigation, an economically accessible P84 co-polyimide was chosen as principle polymer precursor.
N-methyl-2-pyrrolidone (NMP) obtained from Merck (Germany) was utilized as the dissolvable of P84 copolyimide to set up the polymeric membranes. Methanol was utilized as a dissolvable trade amid post-treatment step. The fired tube was utilized as a membrane bolster.

\subsection{Carbon Membrane Preparation}

Polymeric membranes were fabricated from a homogenous dope arrangement comprising of $15 \mathrm{wt} \%$ P84 co-polyimide and $85 \mathrm{wt} \%$ NMP, separately. The polymer arrangement was blended for 24 hours using mechanical mixing. The blend was kept up in a sonicated water shower to expel all rises from the arrangement. Polymer upheld membranes were set up by plunge covering a uniform membrane of the polymeric arrangement over the outer surface of a tubular supported by using dip-coating method. The dip-coating method has been conducted for 45 minutes and the membranes were then dried at $80^{\circ} \mathrm{C}$ for 24 hours. Next, the membranes were drenched with methanol for 2 hours and after that set at $100^{\circ} \mathrm{C}$ for 24 hours inside broiler to permit moderate expulsion of the dissolvable. The dried upheld polymeric membranes were put inside the Carbolite flat tubular heater for carbonization compositions. In the initial step, the membranes were dealt under Argon stream $(200 \mathrm{ml} / \mathrm{min})$ with temperature up to $300^{\circ} \mathrm{C}$ and warming rate of $3^{\circ} \mathrm{C} / \mathrm{min}$. In the second step, the membranes were dealt with temperature up to $600,700,800$ or $900^{\circ} \mathrm{C}$ at a similar warming rate and gas stream.

\subsection{Membrane Characterization}

The pattern of changes in weight reduction amid carbonization was acquired by utilizing thermogravimetric analysis (TGA) using Mettler Toledo 
instrument. The investigation was performed with a heating rate of $10^{\circ} \mathrm{C} / \mathrm{min}$ at the temperature extending from 40 to $900^{\circ} \mathrm{C}$. The cross-area morphology of the polymer and carbon membranes was observed under JEOL JSM-5610LV scanning electron microscopy (SEM).

\subsection{Pure Gas Permeation Measurements}

In this investigation, neat $\mathrm{CO}_{2}, \mathrm{~N}_{2}$, and $\mathrm{CH}_{4}$ gases were used as a sustain courses through the membrane in the gas permeation test. The performance of the membrane can be characterized by means of two important parameters which are permeance and selectivity. The permeance, $P / l$ (GPU) and selectivity, $\alpha$ of the membranes were calculated using the equations as follows.

$$
\begin{gathered}
(P / l)_{i}=\frac{Q_{i}}{\Delta p \cdot A}=\frac{Q}{\eta \pi D l \Delta P} \\
\alpha_{A / B}=\frac{P_{A}}{P_{B}}=\frac{(P / l)_{A}}{(P / l)_{B}}
\end{gathered}
$$

where $P / l$ is the permeance of the membrane, $Q_{i}$ is the volumetric flow rate of gas $i$ at standard temperature and pressure $\left(\mathrm{cm}^{3}(\mathrm{STP} / \mathrm{s})\right), p$ is the pressure difference between the feed side and the permeation side of the membrane $(\mathrm{cmHg}), A$ is the membrane surface area $\left(\mathrm{cm}^{2}\right), n$ is the number of sample in the module, $D$ is the outer diameter of the membrane $(\mathrm{cm})$, and $l$ is the effective length of the membrane $(\mathrm{cm})$. The selectivity, $\alpha$ is defined as the ratio of fast gas permeation to slow gas permeation. The carbon membrane was tested using an in-house gas permeation system. The system consists of a flexible hose, permeation cell, valve, pressure regulator and soap bubble meter. The $8-\mathrm{cm}$ tubular carbon membrane was put inside the tubular module and was supported into the module at sustain weight of 8 bars by pure gas. A tubular stainless-steel module of $14 \mathrm{~cm}$ long was utilized to contain the tubular fired membrane and fitted with elastic O-rings that enabled the membrane to be housed in the module without spillages.

\subsection{RESULTS AND DISCUSSION}

\subsection{Thermal Properties}

TGA gave data about the adjustments in warm strength of P84 co-polyimidebased polymeric membranes. The changes in physical and chemical properties of polymeric membranes during TGA gave an overview of the evolution of carbon membranes from corresponding precursors which provide critical information for designing the pyrolysis protocol of the experiment.

Figure 1 shows the weight reduction of $15 \mathrm{wt} \%$ of precursor with expanding temperature from 30 to $800^{\circ} \mathrm{C}$. As appeared in the figure, TGA investigation was completed for one arrangement which is $15 \mathrm{wt} \%$ P84 copolyimide polymeric membranes and the weight reduction happened in two stages in which the principal corruption of creation of forerunner from its unique weight to $97 \%$ was begun at roughly $35^{\circ} \mathrm{C}$ to $90^{\circ} \mathrm{C}$. At that point, the polymer membrane with grouping of 15 wt $\%$ ended up stable until $300^{\circ} \mathrm{C}$.

The $15 \mathrm{wt} \%$ polymeric membranes were started for second decompose again at the temperature of $300^{\circ} \mathrm{C}$ and end around $800^{\circ} \mathrm{C}$. It was attributed to the decomposition of P84 co-polyimide molecule. Generally, the weight losses happened due to the evolution of $\mathrm{CO}$, $\mathrm{CO}_{2}$ and $\mathrm{CH}_{4}$ during heat treatment process, which caused a cleavage of the benzene ring of P84 co-polyimide- 
based polymeric membrane. Similar results were also obtained by Salleh and Ismail [11]. Four temperatures; 600, 700,800 and $900^{\circ} \mathrm{C}$ were selected, to explore the effects of carbonization temperature on the microstructure and permeation properties of the resultant carbon membranes.

In view of TGA investigation have discovered that adjustment between the temperature scope of glass progress temperature and debasement temperature can viably keep a softening stage amid carbonization for warm plastic polymers, for example, polyimides (PI) as reported by Sazali and collaborators [12]. In this manner, adjustment temperature of $300^{\circ} \mathrm{C}$, which is in the vicinity of 90 and $400^{\circ} \mathrm{C}$ was connected amid adjustment venture to wipe out remaining dissolvable while staying away from polymer liquefying. A thermally stable structure will be made in the membrane grid by crossconnecting amid the adjustment step, which prompts arrangement of deformity free carbon membranes after carbonization. This outcome is in agreement with Barsema et al. [13].

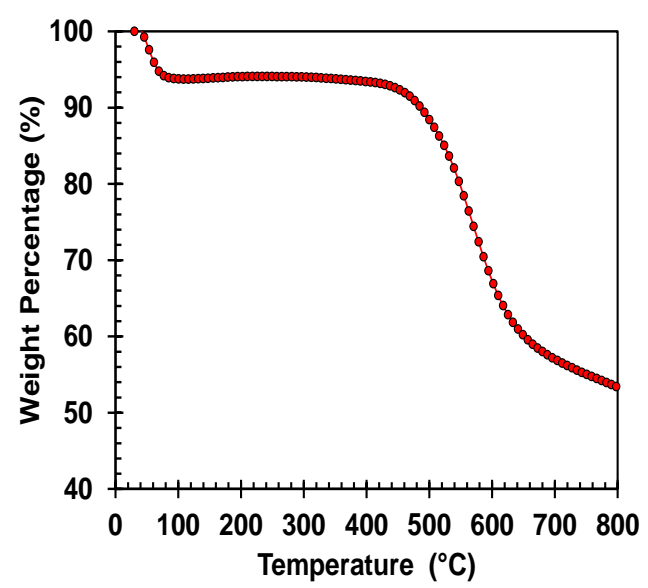

Figure 1 TGA profile for P84 co-polyimide

\subsection{Morphological Structure}

Scanning Electron Microscopy (SEM) was utilized to describe the morphology of P84 co-polyimide-based polymeric and carbon membranes arranged under various carbonization temperature. Figure 2 (a) presents the SEM images of the 15 wt $\%$ P84-based polymeric membrane, while Figure 2 (b)-(e) shows the cross-segment microphotographs of $15 \mathrm{wt} \%$ P84based carbon membranes at 600, 700, 800 and $900^{\circ} \mathrm{C}$.

By looking at the difference between P84-based polymeric membrane and P84-based on carbon membranes with various carbonization temperature, it can be obviously observed that P84based polymeric membrane exhibits cracks and poor rearrangement structures while P84-based carbon shows conservativeness structure and more ordered structure. It demonstrates that the polymer chains shaped have expanded the pressing thickness of the membranes and a portion of the pores wind up thin because of the densification of carbon structure. It is similar compared to the work of Sazali and coworkers [14]. As the final carbonization temperature increases, the gas will pass through the membrane structure according to their kinetic diameter. Thus, the increment of carbonization final temperature would produce the carbon membrane with a higher permeability and selectivity.

As shown in Figure 2 (b)-(e), their structures were more compact when the pyrolysis temperature was increased from CM-600 to CM-800. However, when the pyrolysis temperature was increased to CM-900, it became less compact and the structure was collapsed. This was due to heating at a higher temperature caused the pores to shrink and finally disappeared. It was supported by research done by Centeno and Fuertes (2004) in which they reported that the pores will enlarge at the temperature range $700-800^{\circ} \mathrm{C}$. Thus, at the temperature around $1000^{\circ} \mathrm{C}$, the porosity of carbonized material was mainly closed [15]. 

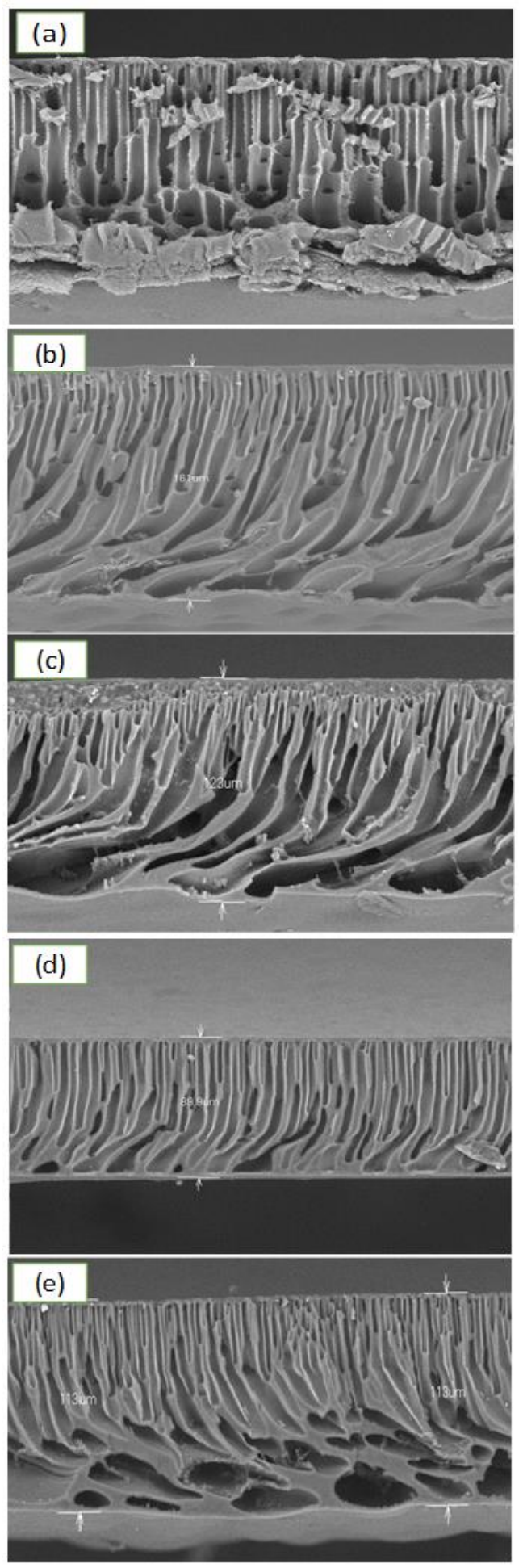

Figure 2 SEM images (a) $\mathrm{P} 84$ polymeric membrane (b) $\mathrm{CM}-600^{\circ} \mathrm{C}$, (c) $\mathrm{CM}-700^{\circ} \mathrm{C}$, (d) $\mathrm{CM}-800^{\circ} \mathrm{C}$ (e) $\mathrm{CM}-900{ }^{\circ} \mathrm{C}$

\subsection{Gas Permeation Measurements}

The permeability of three pure gases with different molecular sizes; $\mathrm{CO}_{2}$
(3.30), $\mathrm{N}_{2}$ (3.64), and $\mathrm{CH}_{4}$ (3.80), through the resulting carbon membranes were measured, after each carbonization step. The gas permeance of the prepared carbon membranes would follow the order of $\mathrm{CO}_{2}>\mathrm{N}_{2}>$ $\mathrm{CH}_{4}$, which were in accordance with their kinetic diameters. Similar trends were also reported by Favvas's and group [16].

As tabulated in Table 1, P84-based tubular supported carbon membranes demonstrated a superior performance property compared with the polymeric membranes. The P84 with the composition of $15 \mathrm{wt} \%$ demonstrated a decent performance execution because of the pressing thickness of the membrane, in this way enabling the gases to saturate through the membrane adequately. It shows that an expansion in carbonization temperature will build the permeance and selectivity of carbon membranes. Table 1 shows gas permeation results for P84 polymeric and carbon membrane. The results indicated that the carbon membrane with carbonization temperature of $800^{\circ} \mathrm{C}$ showed superior selectivity compared to the other carbonized temperature. This was due to its pore system which contained wide-ranging openings with narrow constriction [14].

In general, the gas permeability for neat PI polymeric membranes had been obviously lowered compared to carbon membrane. As the carbonization temperature increased, the carbon membrane turned out to be more permeable, resulting in high selectivity. This demonstrated that pores and carbon structure of the carbon membrane wind up inflexible, smaller and a portion of the pores may change into shut pores amid the carbonization. On the other hand, when higher carbonization temperature was applied, it cause the pores to vanish. This 
Table 1 Gas permeation results for P84 polymeric and carbon membrane

\begin{tabular}{cccccc}
\hline & \multicolumn{3}{c}{ Permeance (GPU) } & \multicolumn{2}{c}{ Selectivity } \\
\cline { 2 - 6 } & $\mathbf{C H}_{\mathbf{4}}$ & $\mathbf{N}_{\mathbf{2}}$ & $\mathbf{C O}_{\mathbf{2}}$ & $\mathbf{C O} / \mathbf{C H}_{\mathbf{4}}$ & $\mathbf{C O}_{2} / \mathbf{N}_{\mathbf{2}}$ \\
\hline P84 co-polyimide & $0.68 \pm 4.57$ & $0.70 \pm 5.23$ & $1.13 \pm 6.32$ & $1.66 \pm 3.49$ & $1.61 \pm 4.21$ \\
CM-600 & $1.7 \pm 2.5$ & $1.8 \pm 2.3$ & $55.8 \pm 3.1$ & $32.8 \pm 2.9$ & $31.0 \pm 1.8$ \\
CM-700 & $2.5 \pm 1.5$ & $2.7 \pm 2.2$ & $96.2 \pm 4.5$ & $38.5 \pm 1.8$ & $35.6 \pm 2.7$ \\
CM-800 & $2.8 \pm 2.8$ & $2.9 \pm 4.6$ & $180.8 \pm 3.2$ & $63.2 \pm 5.2$ & $61.3 \pm 1.7$ \\
CM-900 & $2.3 \pm 2.8$ & $2.5 \pm 1.9$ & $131.3 \pm 3.7$ & $57.1 \pm 4.4$ & $52.5 \pm 6.8$ \\
\hline
\end{tabular}

example was in concurrence with the way that the carbonized membranes have a micropore structure that was competent to perceive the diverse active width of gases and builds the selectivity. Comparable discoveries were likewise revealed by Saufi and Ismail, 2004 [17]. Overall, the carbonization temperature of $800^{\circ} \mathrm{C}$ was found to be the best temperature for the fabrication of carbon membrane made of $15 \mathrm{wt} \% \mathrm{P} 84$. Such membrane shows $\mathrm{CO}_{2} / \mathrm{CH}_{4}$ and $\mathrm{CO}_{2} / \mathrm{N}_{2}$ selectivity of $63.2 \pm 5.2$ and $61.3 \pm 1.7$, respectively.

\subsection{CONCLUSION}

Generally, it is well known that the polymeric membrane performance appears to be a trade-off between a selectivity and permeability. Carbon membrane was produced via heat treatment process to improve the molecular structure of the membrane and to increase its ability to separate gases in terms of permeability and selectivity. Carbonization process plays a significant role in the production of carbon membrane. Due to its brittleness, a tube support is used to overcome this problem. Based on the study, there are a few conclusions reached:

(a) P84 co-polyimide is a reasonable precursor for carbon membranes as it can withstand high temperature warm treatment in carbonization process.

(b) The resultant carbon membrane demonstrates smaller pores and shows higher $\mathrm{CO}_{2} / \mathrm{CH}_{4}$, and $\mathrm{CO}_{2} / \mathrm{N}_{2}$ selectivity than the polymeric precursor membrane.

(c) The selectivity of gas sets expanded as the carbonization temperature expanded because of the high minimization of the carbon membrane structure.

(d) The best execution is acquired for carbon membrane arranged at $800^{\circ} \mathrm{C}$ with $\mathrm{CO}_{2} / \mathrm{CH}_{4}$ and $\mathrm{CO}_{2} / \mathrm{N}_{2}$ selectivity of $63.2 \pm 5.2$ and $61.3 \pm 1.7$, separately. However, when carbonization temperature is over $800^{\circ} \mathrm{C}$, it will initiate gas partition. Low carbonization temperature $\left(<600{ }^{\circ} \mathrm{C}\right)$ meanwhile is not able to achieve complete carbonization for membranes.

\section{ACKNOWLEDGEMENTS}

The authors would like to acknowledge the financial aids from the Ministry of Higher Education and Universiti Teknologi Malaysia under Higher Institution Centre of Excellence Scheme (Project Number: R. J090301.7846.4J186), Fundamental Research Grant Scheme (Project Number: R. J130000.7846.4F846) and Research University Grant Scheme (Project Number: Q. J130000.2546.03G69). The authors would also like to acknowledge technical and management support from Research Management Centre (RMC), Universiti Teknologi Malaysia. The authors would also gratefully 
acknowledge the financial support from the Ministry of Higher Education and Universiti Malaysia Pahang under Fundamental Research Grant Scheme (Project Number: Rdu170125).

\section{REFERENCES}

[1] N. H. Ismail, W. N. W. Salleh, N. Sazali, A. F. Ismail. 2018. Development and Characterization of Disk Supported Carbon Membrane Prepared by One-step Coatingcarbonization Cycle. J. Ind. Eng. Chem. 57: 313-321.

[2] N. Sazali, W. N. W. Salleh, A. F. Ismail, N. A. H. M. Nordin, N. H. Ismail, M-A. Mohamed, F. Aziz, N. Yusof, J. Jaafar. 2018. Incorporation of Thermally Labile Additives in Carbon Membrane Development for Superior Gas Permeation Performance. J. Nat. Gas Sci. Eng. 49: 376-384.

[3] X. Q. Cheng, Z. X. Wang, X. Jiang, T. Li, C-H. Lau, Z. Guo, J. Ma, L. Shao. 2018. Towards Sustainable Ultrafast Molecularseparation Membranes: From Conventional Polymers to Emerging Materials. Prog. in Mater. Sci. 92: 258-283.

[4] P. K. S. Mural, G. Madras, S. Bose. 2018. Polymeric Membranes Derived from Immiscible Blends with Hierarchical Porous Structures, Tailored Bio-interfaces and Enhanced Flux: Potential and Key Challenges. Nano-Structures \& Nano-objects. 14: 149-165.

[5] B. A. Pulido, C. Waldron, M. G. Zolotukhin, S. P. Nunes. 2017. Porous Polymeric Membranes with Thermal and Solvent Resistance. J. Membr. Sci. 539: 187-196.
[6] M. B. Rao, S. Sircar. 1993. Nanoporous Carbon Membranes for Separation of Gas Mixtures by Selective Surface Flow. J. Membr. Sci. 85: 253-264.

[7] Y. Zhang, J. Sunarso, S. Liu, R. Wang. 2013. Current Status and Development of Membranes for $\mathrm{CO}_{2} / \mathrm{CH}_{4}$ Separation: A Review. Int. J. Greenh. Gas Con. 12: 84107.

[8] V. C. Geiszler, W. J. Koros. 1996. Effects of Polyimide Pyrolysis Conditions on Carbon Molecular Sieve Membrane Properties. Ind. \& Eng. Chem. Res. 35: 29993003.

[9] J. B. S. Hamm, A. Ambrosi, J. G. Griebeler, N. R. Marcilio, I. C. Tessaro, L. D. Pollo. 2017. Recent Advances in the Development of Supported Carbon Membranes for Gas Separation. Int. J. Hyd. Energy. 42: 24830-24845.

[10] C. Zhang, Z. Geng, J. Ma. 2013. Self-assembly Synthesis of Ordered Mesoporous Carbon Thin Membrane by a Dip-coating Technique. Micro. Meso. Mater. 170: 287-292.

[11] W. N. W. Salleh, A. F. Ismail. 2011. Carbon Hollow Fiber Membranes Derived from PEI/PVP for Gas Separation. Sep. Purif. Techol. 80: 541-548.

[12] N. Sazali, W. N. W. Salleh, A. F. Ismail. 2017. Carbon Tubular Membranes from Nanocrystalline Cellulose Blended with P84 Copolyimide for $\mathrm{H}_{2}$ and he Separation. Int. J. Hyd. Energy. 42: 9952-9957.

[13] J. N. Barsema, S. D. Klijnstra, J. H. Balster, N. F. A. van der vegt, G. H. Koops, M. Wessling. 2004. Intermediate Polymer to Carbon Gas Separation Membranes based on Matrimid PI. J. Membr. Sci. 238: 93-102. 
[14] N. Sazali, W. N. W. Salleh, N. A. H. M. Nordin, A. F. Ismail. 2015. Matrimid-based Carbon Tubular Membrane: Effect of Carbonization Environment. $J$. Ind. Eng. Chem. 32: 167-171.

[15] T. A. Centeno, J. L. Vilas, A. B. Fuertes. 2004. Effects of Phenolic Resin Pyrolysis Conditions on Carbon Membrane Performance for Gas Separation. J. Membr. Sci. 228: 45-54.
[16] E. P. Favvas, N. S. Heliopoulos, S. K. Papageorgiou, A. C. Mitropoulos, G. C. Kapantaidakis, N. K. Kanellopoulos 2015. Helium and Hydrogen Selective Carbon Hollow Fiber Membranes: The Effect of Pyrolysis Isothermal Time. Sep. Purif. Technol. 142: 176-181.

[17] S. M. Saufi, A. F. Ismail. 2004. Fabrication of Carbon Membranes for Gas SeparationA Review. Carbon. 42: 241-259. 